\title{
Solidariedade crítica e voluntariado orgânico: outra possibilidade de intervenção societária
}

\section{Critical solidarity and organic volunteering: another form of social intervention}

Lucilda Selli

Professora e pesquisadora do Programa de Pós-Graduação em Saúde Coletiva Universidade do Vale do Rio dos Sinos - Unisinos Av. Unisinos, 950

93022-000 São Leopoldo - RS - Brasil lucilda@unisinos.br

\section{Volnei Garrafa}

Professor de bioética e pesquisador do Programa de Pós-Graduação em Ciências da Saúde

Faculdade de Ciências da Saúde da

Universidade de Brasília

70919-970 Brasília - DF - Brasil

bioética@unb.br
SELLI, L.; GARRAFA, V.: Solidariedade crítica e voluntariado orgânico: outra possibilidade de intervenção societária. História, Ciências, Saúde - Manguinhos, v. 13, n. 2, p. 239-51, abr.-jun. 2006.

$\mathrm{Na}$ atualidade, as práticas da solidariedade e do voluntariado estão difundidas em quase todo o mundo e das mais diferentes maneiras: algumas de forma assistencialista, outras mais comprometidas com mudanças de menor ou maior profundidade. Este trabalho desenvolve-se sob três perspectivas: 1) aproximação da solidariedade em um enfoque histórico, buscando sua gênese e suas características principais;

2) identificação do voluntariado ao longo do tempo, destacando o processo que deu origem à atividade voluntária no Brasil, enfatizado sua importância social;

3) proposta da solidariedade crítica e do voluntariado orgânico, como mecanismos de ação interventiva e transformação societária. Com base nesta visão, busca-se oferecer elementos que dêem clareza às motivações que levam os voluntários a exercerem tal atividade, e apresentar a solidariedade crítica como valor que motiva as pessoas e associações em seus empreendimentos sociais cotidianos.

PALAVRAS-CHAVE: solidariedade crítica; voluntariado orgânico; transformação societária.

SELLI, L.; GARRAFA, V.: Critical solidarity and organic volunteering: another form of social intervention.

História, Ciências, Saúde - Manguinhos, v. 13, n. 2, p. 239-51, Apr.-June 2006.

The practices of solidarity and volunteerism have spread throughout most of the world today, finding expression in diverse ways: some are 'assistentialist' in form, while others reveal more of a commitment to change, of a greater or lesser order. This paper explores three perspectives:

1) a look at solidarity from a historical approach that seeks to identify its genesis and main characteristics; 2) an identification of volunteerism over time, with special attention paid to the process of its emergence in Brazil and its social value; 3) the proposal of critical solidarity and organic volunteering as ways of intervening in and transforming society. From this perspective, the text endeavors to elucidate what motivates volunteers to engage in this activity; it presents critical solidarity as a value that motivates people and associations in their day-to-day social ventures.

KEYWORDS: critical solidarity; organic volunteering; social transformation. 
$\mathrm{O}$ interesse pela proposta da solidariedade crítica como valor a orientar o serviço voluntário orgânico tem, entre outras justificativas, motivações provenientes da realidade social e outras alicerçadas em vivências pessoais. A adjetivação crítica, no contexto deste trabalho, diz respeito à capacidade do agente de discernir, ou seja, de possuir critérios capazes de ajudá-lo a discriminar as dimensões social e política que estão indissociavelmente presentes na relação solidária. Assim, a solidariedade não se esgota enquanto relação típica da sociedade civil. Ao contrário, possui um elemento político que tem como referência o Estado. A capacidade de entender essa dimensão política, que se refere à cidadania e à possibilidade de intervir de forma ativa na definição de políticas públicas, também caracteriza essa dimensão crítica. $\mathrm{O}$ conceito de voluntariado orgânico, por sua vez, foi construído por analogia ao conceito de intelectual orgânico desenvolvido por Gramsci (1979) e é entendido como uma participação ativa e beneficente das pessoas que desenvolvem a atividade voluntária na construção das condições necessárias à democratização efetiva do Estado, em todas as suas dimensões, em nosso caso específico, na área da saúde.

A crença de que existe um potencial a ser explorado entre os prestadores de trabalho voluntário para uma adequada utilização de suas capacidades, as quais podem atuar no enfrentamento da questão social, que, hoje, no Brasil, é premente e demanda soluções que reduzam a exclusão e a desigualdade social, respalda a proposta. A leitura que a sociedade brasileira faz da atividade voluntária ainda está plena de estereótipos e preconceitos ligados a representações sociais que foram construídas ao longo do tempo e fazem parte de nossa cultura política.

A solidariedade que se busca compreender e propor como motivação central para a atuação voluntária em organizações da sociedade civil é um valor que está ligado à organização da sociedade moderna. Esta, por definição, não deriva de doutrinas políticas ou religiosas, que, por sua natureza, são parciais. Contudo, é um valor central e serve como motivador para as associações voluntárias de todos os tipos que tenham como objetivo principal trazer benefícios aos necessitados. Em sua dimensão ética, designa um valor imanente à condição humana, que decorre do fato dos seres humanos viverem em comunidade, portanto, de viverem em relações interdependentes (Prudente, 2000). A crença de que a atividade voluntária nos marcos da solidariedade é elemento importante para aqueles que buscam a justiça social, aliada ao interesse pela compreensão do fenômeno, e a tentativa da Organização Mundial da Saúde em ampliar a ação social ao declarar 2001 o Ano Internacional do Voluntariado e com isso legitimar o interesse pelo 'outro', levaram-nos a estudar e aprofundar tal tema. 
No campo da saúde, os princípios e valores que regulamentam a conduta dos profissionais pautaram-se pelo binômio beneficência e caridade. A beneficência sintetizando a deontologia médica hipocrática e a caridade representando os valores clássicos da tradição cristã na área da saúde. Tais representações sociais, passando pelo mundo político, estabeleciam uma configuração específica ao direito nas questões ligadas à saúde. Exemplificado na relação médico-paciente, o pólo ativo dava-se na figura do médico e o pólo passivo encarnava-se na figura do paciente. As normas legais, por seu turno, cristalizavam, juridicamente, tais representações. O marco decisivo que, no bojo do processo de secularização da sociedade brasileira, modificou o status quo foi a Constituição da República Federativa do Brasil de 1988. Esse diploma fundamental sintetiza as novas representações ético-políticas da sociedade brasileira. $\mathrm{O}$ ordenamento jurídico brasileiro passou, aos poucos, a se adequar à nova realidade. Pessoas e cidadãos passaram a ter novos direitos tutelados pelo Estado. Na saúde, o impacto se fez sentir com a introdução de novas formas de relacionamento em geral, e na relação médico-paciente em particular. Tais mudanças nas relações intersubjetivas - em nossa visão, resultantes de um processo de secularização aliado à ampliação do individualismo liberal e democrático em nosso país - são consentâneas com o paradigma representado pelo mundo civilizado e podem ser sintetizadas pelos valores clássicos da Igualdade e da Liberdade.

Com a progressiva mudança na cultura política e social, a sociedade brasileira encontra-se hoje num período de valorização e ampliação do espaço da sociedade civil. O surgimento de novas organizações sociais, aliadas às tradicionalmente existentes, e a ampliação da quantidade de voluntários e de espaços para a prática do voluntariado sinalizam que a sociedade brasileira passa a enfrentar o desafio dos inúmeros problemas sociais existentes no país. São, portanto, as organizações sociais, no espaço da sociedade civil, novos agentes de mudança (Roca, 1994).

Este trabalho insere-se no contexto descrito. Busca propor, entre os novos princípios e valores associados à sociabilidade moderna, aquele que melhor se coaduna com relações interpessoais guiadas pela igualdade e liberdade, qual seja a solidariedade. Também, é de interesse tornar claras as motivações que norteiam a conduta dos voluntários na expectativa de que estas atividades se ampliem, com evidentes benefícios sociais, a exemplo de outros países que já possuem uma 'tradição' de voluntariado, nos moldes contemporâneos.

\section{Solidariedade em perspectiva histórica}

O tema da solidariedade tem várias interpretações no mundo de hoje. A solidariedade, como valor ético, fazendo uma retrospectiva 
histórica, está presente na filosofia política do Iluminismo. JeanJacques Rousseau, por exemplo, via na solidariedade a capacidade de manter unida uma coletividade composta de indivíduos isolados. Na Revolução Francesa, o ideal da fraternidade, contraposto ao individualismo e ao egoísmo burguês, possuía características da solidariedade como se conhece hoje. Porém, foi no pensamento anarquista que a solidariedade encontrou um amplo espaço para a explicação de uma característica usual em nossa espécie: as relações de ajuda mútua e apoio.

Foi o príncipe russo Peter Kropotkin, convertido ao Anarquismo, ideologia política comum na Rússia do final do século XIX, que procurou dar um fundamento natural à solidariedade. Kropotkin procura demonstrar que Thomas Hobbes, ao descrever o "estado de natureza" em que se encontram os seres humanos na ausência do Estado como uma "guerra de todos contra todos", diz uma meia verdade. A ajuda mútua, ou solidariedade, também possui um papel fundamental na evolução. Diz ele: "Se fizermos um teste indireto e perguntarmos à Natureza quem é mais apto, se as espécies que vivem constantemente em guerra ou as que se apóiam mutuamente, veremos de imediato que os animais que adquirem o hábito da ajuda mútua são os mais aptos" (Kropotkin \& Ridley, 2000). Nesta mesma linha de raciocínio, Camps (1996) entende que a solidariedade é uma lei da natureza, um sentimento irrefutável de adesão ao grupo e à espécie. Esse fundamento permite conceber a moral não como um compromisso de deveres e normas, mas como a busca do prazer e a repulsa da dor, isto é, uma moral utilitária, porém que não tem como sujeito do prazer o indivíduo, mas a sociedade. Infere Camps (1996, p. 37): "é certo que em toda a sociedade humana, a solidariedade é uma lei da natureza infinitamente mais importante que a luta pela existência cuja virtude nos cantam os burgueses em seus refrãos a fim de embrutecer-nos o mais completamente possível". A solidariedade seria intrínseca a todos os que participam da condição humana. As assimetrias, as desigualdades, mobilizam nas pessoas essa dimensão, principalmente com os membros menos favorecidos e mais vulneráveis da sociedade.

O conceito de solidariedade também esteve presente na sociologia do século XIX. Durkheim (1987), sociólogo francês, fez da solidariedade um conceito importante para designar as forças que mantêm unidos os membros de uma coletividade. Quando os indivíduos vivem em sistemas econômicos marcados pela ausência de especialização, entre eles (divisão do trabalho), o que os mantém unidos é a solidariedade mecânica, que, segundo o autor, caracteriza-se pelo compartilhamento de idéias comuns, costumes, crenças, hábitos. Com a divisão do trabalho e a conseqüente especialização dos trabalhadores, surge a solidariedade orgânica que, como o próprio nome denota, faz que os indivíduos, sendo interdependentes, 
comportem-se como um organismo. Os dois tipos sociológicos de solidariedade descritos por Durkheim solidificam a coesão interna e os vínculos existentes entre grupos sociais definidos. Essa forma de solidariedade impõe-lhe limites por restringi-la aos interesses de determinada coletividade.

$\mathrm{Na}$ busca de um contraponto ao individualismo liberal, alguns pensadores católicos no final do século XIX, preocupados com o papel da doutrina social da Igreja, desenvolveram uma corrente de pensamento chamada 'solidarismo'. O interesse era o de fazer acontecer um equilíbrio entre o individualismo liberal e o coletivismo marxista (Wildmann, 1961). No bojo da questão, estava o interesse da Igreja Católica pelo direito à igualdade de todos os seres humanos. Tanto a doutrina social da Igreja quanto a teologia da libertação têm em sua gênese a solidariedade com as vítimas do sistema liberal capitalista (Anjos, 2000). Na compreensão da teologia da libertação, a solidariedade autêntica é a solidariedade entre desiguais. É uma solidariedade que postula transformações estruturais que corrigem as assimetrias existentes.

A atividade voluntária orgânica deve, em princípio, ter como motivação o exercício da solidariedade crítica. Berlinguer (1996) lembra que todo indivíduo tem direitos próprios e, portanto, não pode ser usado ou manipulado por outros. A solidariedade crítica não aceita que diferenças naturais (sexo, raça, cor, idade etc.) ou sociais (renda, cultura, descendência etc.) possam levar a tratamentos desiguais entre os indivíduos, tanto no mundo privado quanto no mundo público. Na Constituição da República Federativa do Brasil de 1988, a igualdade é assim descrita: Art. 5ํㅜ “Todos são iguais perante a lei, sem distinção de qualquer natureza".

A atividade voluntária orgânica constitui, portanto, um espaço singular, em que os sujeitos, motivados pela solidariedade crítica, como valor que orienta seu agir, são fautores da justiça. $\mathrm{O}$ valor que deve nortear a ética da responsabilidade há de ser a solidariedade. Nas palavras de Carvalho et al. (1998, p.32): "uma ética solidária, baseada na cooperação e na qualidade do que se produz, do que se vive e do que se pensa". Uma ética que nasce, assim, de um sentimento de responsabilidade. Pela solidariedade crítica, pretende-se-como refere a raiz grega do termo solidus - construir, através da prática da solidariedade, uma sociedade mais igualitária, sólida, inclusiva (Gafo, 1997).

Sintetizando as observações teóricas referidas, enumeram-se algumas características do conceito de solidariedade nos moldes que respaldam a presente proposta: é um valor próprio da pessoa humana, que tem origem em sua dignidade; independe de determinações, prescrições e crenças religiosas, que criam comunidades morais distintas e, na maioria das vezes, antagônicas. É, tal como os direitos civis (vida, liberdade, direito de expressão etc.), um valor universal; é exercida pela pessoa, na sociedade civil, e exercê-la 
independe, portanto, do papel de cidadão, de crente etc.; é praticada entre pessoas que comungam tanto idênticas quanto diferentes moralidades; sua prática deve estabelecer uma relação horizontal (unívoca); situa-se entre a idéia de imparcialidade - ser movido pelo bem geral do outro - e a idéia de benefício mútuo - reciprocidade.

\section{A importância social do voluntariado}

O conceito de voluntariado é utilizado, nos dias de hoje, conforme Szazi (2000), com o objetivo de designar as condutas das pessoas que prestam serviços não-onerosos na sociedade civil e em diferentes áreas, onde tais serviços são necessários. A atividade voluntária organizada surgiu na Europa, quando a urbanização e o êxodo rural associado à industrialização, em seus primórdios, trouxeram conseqüências negativas para amplas parcelas da sociedade. No mundo rural pré-industrial algumas instituições eram responsáveis pela solução de problemas, como fome, doença e catástrofes naturais, que pudessem atingir indivíduos ou grupos. A família extensa de caráter patriarcal, as instituições religiosas ou mesmo a comunidade tinham tal atribuição. Não existia, ainda, um Estado capaz de propor políticas públicas de amparo aos necessitados.

Do ponto de vista histórico, o Estado moderno surgiu no Ocidente, na maioria dos casos, nos séculos XIV a XVI - pouco antes do início das mudanças econômicas e sociais trazidas pela industrialização, baseada no sistema econômico capitalista. A Inglaterra, no século XVII, já formulara uma doutrina política liberal para o Estado, política essa centrada no indivíduo. O liberalismo político criara um Estado para tutelar os direitos individuais e garantir a atividade econômica. A questão social que surgiu na Europa com a migração e a urbanização (fome, desemprego, miséria etc.) tinha de ser administrada pela própria sociedade civil, e foi nesse contexto que surgiram as associações voluntárias de caráter social.

Além de contribuírem para a solução de questões sociais, as organizações voluntárias tiveram um papel importante na defesa da sociedade contra o exercício arbitrário do poder do Estado. Intermediárias entre o indivíduo isolado e a sociedade política, coube às associações voluntárias (partidos políticos, sindicatos, instituições de intelectuais, associações religiosas etc.) promover a defesa da sociedade civil contra o poder arbitrário do Estado. Bobbio (em Bobbio et al., 1995) assegura que com o surgimento e ampliação da democracia política na Europa, a partir da segunda metade do século XIX, mais importante tornou-se o papel das associações voluntárias.

Segundo Weffort (1998), o processo de democratização política experimentado na Europa muito deveu a elas. O mesmo pode se dizer dos Estados Unidos. Adeptos do liberalismo político, os construtores do Estado norte-americano reservaram um amplo espaço à 
auto-organização da sociedade civil, dotando as comunidades de um grande poder para gerir seus destinos sem a interferência pública.

O cientista político norte-americano Robert A. Dahl (in Bobbio et al., 1995) entende que são necessários muitos centros de poder, dos quais nenhum possa ser inteiramente soberano. Embora na perspectiva do pluralismo americano só o povo seja o legítimo soberano, ele não deve ser nunca um soberano absoluto. A teoria e a prática do pluralismo americano tendem a afirmar que a existência da multiplicidade de centros de poder, nenhum deles totalmente soberano, ajudará a refrear o poder, a garantir o consenso de todos e a resolver pacificamente os conflitos.

No constitucionalismo moderno, o direito de associação é um dos múltiplos direitos civis tutelados pelo Estado. A Constituição da República Federativa do Brasil de 1988 assim se expressa com relação ao tema em seu Art. 5을 Inciso XVII: “é plena a liberdade de associação para fins lícitos, vedada a de caráter paramilitar"; e no Inciso XVIII: "a criação de associações e, na forma da lei, a de cooperativas independe de autorização, sendo vedada a interferência estatal em seu funcionamento". O espaço deixado ao Estado pela doutrina liberal é eminentemente negativo: não-interferência no mundo privado.

O Brasil, embora colonizado por um país 'europeu', teve um outro destino histórico. Na tradição política portuguesa, influenciada por uma extensa ocupação árabe, o Estado ocupava não só o espaço que lhe cabia na vida social, como também o espaço do que hoje se chama sociedade civil. Com uma tradição política distinta da sociedade liberal cujo modelo é a Inglaterra, tal forma de dominação política, transportada para o além-mar, estabeleceu as características principais das relações entre Estado e sociedade civil neste país, que se mantêm até os dias de hoje. Dentre elas, sobressai o 'Culto ao Estado', como agente capaz de não só estabelecer a paz social e a justiça, mas também de produzir riqueza, assistir os desvalidos e, no limite, trazer a felicidade a todos os seus membros, ao menos no discurso. (Schwartzman, 1988).

Na díade Estado-sociedade civil, o pólo ativo é o Estado, em seus três níveis organizativos: federal, estadual e municipal. Tal processo trouxe para os membros da sociedade civil uma fraca capacidade organizativa na solução de seus problemas e na defesa de seus interesses, e esse traço cultural percorreu toda a nossa história política. A sociedade civil brasileira é assim descrita por Schwartzman (1988, p. 16):

Diante de um Estado com estas características, como se estrutura a sociedade? Em parte, ela segue uma dinâmica própria, que não se explica nem se entende pelo que ocorre no nível político. $\mathrm{O}$ País passou da escravatura para o trabalho livre, por um processo dramático de deslocamento populacional do campo para 
as grandes cidades [ver Tabela 1], o estímulo à imigração, desenvolveu um parque industrial de grandes proporções na região centro-sul, e não se pode dizer que tudo isto ocorreu por decisão ou intenção dos governos ainda que o estado neopatrimonial tratasse sempre de influenciar ou condicionar estes processos.

O autor chama a atenção para a tradição estatizante da cultura política vigente na sociedade brasileira. O Estado é quase tudo; a sociedade, quase nada. Prova disso é o pequeno papel desempenhado pelos partidos políticos e outras associações voluntárias em nossa história. Apenas a Igreja conseguiu ter um peso político relevante. Mas, como lembra Dreher (2000), na tradição política portuguesa a Igreja fazia parte do Estado.

A questão social, segundo Bobbio (em Bobbio et al., 1995), foi encampada por um Estado marcado pelo paternalismo e assistencialismo, onde cabia a ele a solução dos problemas sociais. Os limites de tais práticas tanto paternalistas quanto assistencialistas, segundo Schwartzman (1988, p. 54), logo se fizeram sentir. Em suas palavras: "Estas transformações tão intensas [ver Tabela 1] não poderiam deixar de colocar em crise a relação de simbiose e dependência que havia se estabelecido no passado entre o Estado brasileiro e a Sociedade Civil. Entra em crise a administração patrimonial clássica, formalista, pesada, ineficiente e voltada para a distribuição de empregos e privilégios". O Estado agora é chamado a gerir com eficiência grandes aglomerados urbanos, proporcionar infra-estrutura a uma economia moderna em expansão, regular um sistema financeiro extremamente complexo, e assim por diante. $\mathrm{O}$ antigo sistema corporativista, que implicava um pacto de conveniência mútua entre o Estado e alguns setores mais organizados da sociedade, também entra em colapso: o número de participantes aumenta, os recursos e privilégios a serem distribuídos não crescem na mesma proporção. O'neomercantilismo', conforme Weffort (1998), também sofre. Sua inerente ineficiência, os altos níveis de corrupção, tudo isso é aceito e tolerado quando a economia se expande, e o que uns ganham não chega a ser necessariamente retirado de outros. Porém, quando os recursos se tornam mais escassos, quando os mecanismos inflacionários de financiamento do dispêndio público colocam em risco a ordem econômica e social, aumenta a pressão por maior eficiência, racionalidade e previsibilidade das ações do governo.

$\mathrm{O}$ autor refere-se a um período da política brasileira que se inicia nos anos 40 e se prolonga até 1964, em que teve vigência o chamado 'Pacto Populista'. Iniciado com Getúlio Vargas, o populismo tinha a função de incorporar as massas urbanas ao processo político de forma que nele não tivessem uma participação autônoma. Era, portanto, mobilizador dentro de uma relação personalista, em que não havia ou, quando havia, era frágil, a mediação dos partidos políticos organizados. Por sua vez, o populismo, em todas as suas versões, é 
conciliador do ponto de vista social; exclui as lutas entre classes sociais e apela para um conceito mítico de 'povo'. Sua função mais importante, contudo, como ilustra o caso brasileiro, é fazer a mediação política diante de um processo de crescimento econômico acelerado, no contexto de uma mão-de-obra oriunda do campo, com baixos níveis de qualificação e extremamente abundante.

Com salários baixos, num processo de acumulação de capital baseado na exploração extensiva dos trabalhadores (grande jornada de trabalho), o Estado passa a proteger os trabalhadores (legislação trabalhista para os trabalhadores urbanos); amplia a saúde fornecida pelo setor público; desenvolve a previdência social; amplia a educação etc. Tudo isso, porém, traduz-se em concessões públicas e não em conquistas políticas dos trabalhadores, tal como ocorreu, por exemplo, na Europa.

Como se pode ver, a 'questão social' no Brasil é recente. Num primeiro momento, tratava-se de incorporar as emergentes massas urbanas ao processo político e promover, direta e indiretamente, um processo de industrialização acelerado. A industrialização brasileira foi tardia em comparação com os países europeus. Iniciando por volta de 1930, quase dois séculos separam-nos da industrialização da Inglaterra, por exemplo. A migração maciça, a urbanização e o crescimento das cidades originam-se nesse período (Faoro, 2000). A partir daí, o crescimento da população total e da população urbana é, no mínimo, impressionante [ver Tabela 1]. É nesse momento que surge, com toda força, a 'questão social' brasileira.

Nesse período, torna-se necessário dotar o país de infra-estrutura urbana capaz de absorver o crescimento da população, possibilitando uma vida com um mínimo de dignidade para as pessoas. Também os serviços públicos essenciais são incapazes de acompanhar o crescimento da demanda. A administração da justiça entra em colapso, e a habitação, o saneamento e a previdência, entre outros,

Tabela I - População Total; Urbana/Rural; 1950-2000 (em 103)

\begin{tabular}{cccccccccc}
\hline Ano & $\begin{array}{c}\text { População } \\
\text { total }\end{array}$ & $\begin{array}{c}\text { População } \\
\text { urbana }\end{array}$ & $\begin{array}{c}\text { População } \\
\text { rural }\end{array}$ & \multicolumn{2}{c}{$\begin{array}{c}\text { População total } \\
\text { urbana }\end{array}$} & \multicolumn{3}{c}{ rural } & \multicolumn{3}{c}{ Taxa geométrica, } \\
crescimento ao ano \\
total & urbana & rural \\
\hline 1950 & 51.940 & 18.783 & 33.162 & 36,16 & 63,84 & - & - & - \\
1960 & 70.992 & 31.005 & 38.988 & 45,08 & 54,92 & 3,17 & 5,47 & 1,63 \\
1970 & 94.509 & 52.905 & 41.604 & 55,98 & 44,02 & 2,90 & 5,15 & 0,65 \\
1980 & 121.151 & 82.013 & 39.137 & 67,69 & 32,31 & 2,51 & 4,48 & $-0,61$ \\
1991 & 146.918 & 110.876 & 36.042 & 75,40 & 24,60 & 1,95 & 3,06 & $-0,82$ \\
2000 & 169.544 & 137.697 & 31.847 & 81,22 & 18,78 & 1,44 & 2,19 & $-1,23$ \\
\hline
\end{tabular}

Fonte: IBGE. Censos demográficos de 1950 a 2000. 
passam a ser problemas crônicos do país. Somente quando a possibilidade de tratar a questão social de forma paternalista e demagógica acaba, quando o Estado mostra seus limites e possibilidades, é que se amplia o espaço para a sociedade civil.

A onipresença estatal, mesmo nos dias de hoje, ajuda a explicar a ênfase dada à dimensão da cidadania neste país. Como o Estado é nossa referência fundamental para a solução da questão social, e o cidadão o titular da soberania política, é tentador imaginar que este, ao assumir o controle público, possa utilizá-lo para 'resolver' a questão social. Tudo, portanto, recebe a referência da cidadania: escola cidadã, participação cidadã e assim por diante. A participação da cidadania é um sinal de maturidade política que deve ser saudado. Somente não se pode manter a ilusão, sob nova roupagem e com outra linguagem, de que o Estado irá resolver a questão social em seus múltiplos desdobramentos.

É nesse momento que surge, dentre tantas outras, a possibilidade de ampliação quantitativa e qualitativa do voluntariado. Do ponto de vista quantitativo, pode-se imaginar, num país dominado por uma população jovem, o grande potencial de recursos humanos facilmente mobilizáveis para atender às demandas sociais da população periférica, tanto das pequenas comunidades quanto das metrópoles urbanas. Do ponto de vista qualitativo, pode-se imaginar a capacidade contributiva social de um significativo número de aposentados com alta qualificação.

Neste trabalho, a ênfase às associações voluntárias está dada por sua capacidade de aglutinar esforços da própria comunidade que vemos como aspecto básico para enfrentar os problemas sociais, tão veementes nos dias atuais. Ao mesmo tempo, não se pode concluir apressadamente que seja proposta uma retirada do Estado e de suas políticas sociais. Ao contrário, deseja-se um sinergismo de esforços diante de tão complexa tarefa. Deve-se trabalhar a dimensão da ética aplicada à saúde pública e coletiva, como justiça, cidadania, direitos humanos, liberdade, participação, responsabilidade, solidariedade, radicalidade e tolerância. Nesse sentido, entende-se que o voluntariado orgânico compõe características específicas que o identificam, compreendidas nos seguintes pressupostos: a conduta voluntária é uma ação racional com relação a um valor: a solidariedade crítica; a conduta voluntária orgânica preenche uma série de requisitos, a saber: é exercida na sociedade civil, não tendo como finalidade o poder políti$\mathrm{co}$, direta ou indiretamente, nem qualquer outra forma dele; é na condição de pessoa que o agente dirige-se aos demais membros da coletividade e a seus potenciais beneficiários; é um compromisso unilateral e personalíssimo, que não se liga a nenhuma forma de ativismo (político, social, religioso) que busque no voluntariado uma função instrumental para seus desígnios; não possui, ao menos conscientemente, um conteúdo utilitário; não vê em sua prática a criação de 
uma moeda de troca ou uma forma de barganha psicológica ou religiosa; é uma busca da reciprocidade e da alteridade; uma abertura ao outro e ao fato de participar de um mesmo universo existencial; denota um inconformismo individual para com o status quo que leva a uma ação positiva em favor de mudanças sociais concretas; caracteriza-se por ser uma busca pela justiça dos destinatários da conduta voluntária livre de paternalismo ou de qualquer outra forma de autoritarismo; deve partir de uma postura democrática radical, que vê no outro um igual tanto em dignidade quanto em autonomia para buscar seus fins; deve ver na tolerância o pluralismo ético indispensável à realização, por todos os membros da coletividade, dos fins que considera relevantes para sua existência; busca a ruptura dos antigos parâmetros imobilizantes.

\section{Palavras finais: construção da solidariedade crítica e voluntariado orgânico}

A solidariedade, com a função de orientar as condutas das pessoas, é entendida nesta proposta de estudo como solidariedade crítica, ou seja: solidariedade comprometida, interventiva - que visa à transformação social na busca de políticas públicas democráticas e eqüitativas - e produz mudanças em nível individual e coletivo. As mudanças entendidas como beneficentes para o indivíduo compreendem a busca da justiça. O sujeito da solidariedade, pela prática solidária crítica, estabelece, com os destinatários da atividade voluntária orgânica, relações que lhes possibilitam descobrirem-se como sujeitos capazes de exercerem seus direitos políticos e civis, de liberdade e igualdade. Na medida em que o indivíduo se reconhece como sujeito que possui direitos e deveres, tanto no plano social quanto no político, terá as condições necessárias para fazer suas escolhas e responder pelas conseqüências de suas decisões. Assim, em nível individual, a solidariedade crítica tem o papel de tornar o destinatário da ação solidária consciente de si mesmo, de seus direitos e deveres, como pessoa integrada na sociedade e como cidadão integrado na vida política. O comprometimento com o outro na vida em coletividade supõe abertura total às múltiplas dimensões da realidade, tanto do indivíduo como sujeito, quanto da realidade sociopolítica na qual ele está inserido e exerce seus papéis de pessoa e de cidadão.

A solidariedade crítica é o valor ético que motiva a prática voluntária orgânica; portanto, valor central que motiva a auto-organização social. Como valor que guia as pessoas no exercício da atividade voluntária, constitui um espaço singular para o exercício da cidadania nos marcos de uma democracia participativa.

A solidariedade poderá realizar mudanças político-sociais, entre outras formas, a partir de um voluntariado orgânico, ou seja, por 
meio da ação concreta de grupos organizados de voluntários comprometidos com transformações sociais, com a luta pela inclusão crescente de um maior número possível de cidadãos nas decisões públicas que lhes digam respeito. O conceito de voluntariado orgânico é entendido como participação crítica das pessoas que desenvolvem a atividade voluntária, como contribuição na construção de condições necessárias ao cumprimento dos compromissos do Estado, em todas as suas dimensões, principalmente na prestação de serviços na área da saúde. O aprofundamento da democracia brasileira exige das pessoas uma postura radical no sentido de participarem, de forma efetiva, da condução das atividades públicas. As associações sociais, na medida em que fazem a mediação entre o indivíduo isolado e as instituições públicas, devem funcionar como 'grupos de pressão', na busca da democratização do Estado. Ao voluntariado - organicamente ligado às demandas dos setores populares que necessitam, por um princípio de justiça eqüitativa, de políticas públicas efetivas - cumpre um papel fundamental nesse processo. Sua capacidade organizativa, aliada a uma clara percepção de que a solução dos problemas sociais passa necessariamente pela via política, estabelece-lhe um papel pedagógico no esclarecimento de direitos constitucionais fundamentais aos setores populares.

A atividade voluntária, nessa perspectiva, deve ser acompanhada pelo comprometimento próprio de quem entendeu o seu papel na sociedade civil, como porta-voz das aspirações dos segmentos que não possuem voz na sociedade. A força autêntica do voluntariado orgânico vem do espírito de comprometimento solidário na busca da liberdade efetiva e da igualdade social, pressuposto de uma sociedade que se pretende liberal e democrática. Torna-se urgentemente necessária a presença ativa da sociedade civil na discussão das prioridades sociais. $\mathrm{O}$ voluntariado orgânico, mo-vido pela solidariedade crítica, tem um papel pioneiro na construção de uma sociedade comprometida com o bem-estar de seus membros e de um Estado com a participação efetiva da cidadania nas decisões de interesse coletivo. Nesse sentido, o estudo procura desmitificar a visão tradicional de voluntariado, focalizando-o sob uma visão orgânica. O voluntariado orgânico não objetiva substituir o Estado no seu compromisso público; constitui, na verdade, uma forma complementar de apoio às atividades relacionadas com a organização e o bem-estar social. A solidariedade crítica, assumida por grupos voluntários e outras associações da sociedade civil, constitui uma forma complementar às organizações do Estado, e se traduz num apoio às atividades públicas que visam promover o bem-estar social e a cidadania. 


\section{REFERÊNCIAS BIBLIOGRÁFICAS}

Anjos, F. M. 2000

Berlinguer, G. 1996

Bobbio, N. et al. 1995

Brasil

1996

Camps, V.

1996

Carvalho, E. A. et al. 1998

Dreher, $M$. 2000

Durkheim, E. 1987

Faoro, R. 2000

Gafo, J. 1997

Gramsci, A. 1979

Kropotkin, P.; Ridley, $M$. 2000

Prudente, G. M. 2000

Roca, G. J. 1994

Schwartzman, S. 1988

Szazi, E. 2000

Weffort, F. (org.) 1998

Wildmann, G. 1961

Ullmann, R.; . Bohnen, A 1993
Bioética nas desigualdades sociais.

In: Garrafa, V.; Costa, S. I. F. (org.). A bioética no século XXI. Brasília: UnB.

Ética da saúde.

(Trad. Shirley Morales Gonsalves.) São Paulo: Hucitec.

Dicionário de política.

(Trad. Carmen C. Varrialle, Gaetano lo Mônaco, João Ferreira, Luiz Guerreiro Pinto Caçais e Renzo Dini. Coord. da trad. João Ferreira.) 7.ed. Brasília: UnB. v. I, II.

Constituição da República Federativa do Brasil de 1988.

São Paulo: Saraiva.

Virtudes públicas.

Madrid: Piliar Cortés.

Ética, solidariedade e complexidade.

São Paulo: Palas Athena.

O papel da Igreja nos 500 anos.

Unisinos em Revista - um Horizonte de Saber, n. 67, dez., p. 24.

A geração da passagem do século.

In: Raymond, A. As etapas do pensamento sociológico.

(Trad. Sérgio Bath.) 2. ed. São Paulo: Martins Fontes; Brasília: UnB.

Os donos do poder: formação do patronato político brasileiro.

10. ed. São Paulo: Globo. v. I.

Los princípios de justicia y solidaridad en bioética.

Revista Persona y Sociedad, v. XI, n. 3, Dic., p. 13-55.

Os intelectuais e a organização da cultura.

Rio de Janeiro: Civilização Brasileira.

As origens da virtude.

São Paulo: Record.

Bioética - conceitos fundamentais.

Porto Alegre: Ed. do Autor.

Solidaridad y voluntariado.

Maliaño (Cantabria): Sal Terrae.

Bases do autoritarismo brasileiro.

3. ed. Rio de Janeiro: Campus.

Terceiro setor: regulação no Brasil.

São Paulo: Peirópolis.

Os clássicos da política: Maquiavel, Hobbes, Locke, Montesquieu, O federalista. 9. ed. São Paulo: Ática. v. I.

Personalismus, solidarismus und Gesellschaft.

Wien: Verlag Herder.

O solidarismo.

São Leopoldo (RS): Unisinos. 